\title{
Longevity-Related Gene Transcriptomic Signature in Glioblastoma Multiforme
}

\author{
Manal S. Fawzy (D, ${ }^{1,2}$ Dahlia I. Badran (D), ${ }^{1,3}$ Essam Al Ageeli, ${ }^{4}$ Saeed Awad M. Al-Qahtani, ${ }^{5}$ \\ Saleh Ali Alghamdi, ${ }^{6}$ Ghada M. Helal, ${ }^{7}$ and Eman A. Toraih $\mathbb{1 0}^{3,8}$ \\ ${ }^{1}$ Department of Medical Biochemistry, Faculty of Medicine, Suez Canal University, Ismailia 41522, Egypt \\ ${ }^{2}$ Department of Medical Biochemistry, Faculty of Medicine, Northern Border University, Arar, Saudi Arabia \\ ${ }^{3}$ Center of excellence in Molecular and Cellular Medicine, Faculty of Medicine, Suez Canal University, Ismailia, Egypt \\ ${ }^{4}$ Department of Clinical Biochemistry (Medical Genetics), Faculty of Medicine, Jazan University, Jazan, Saudi Arabia \\ ${ }^{5}$ Department of Physiology, Faculty of Medicine, Taibah University, Almadinah Almunawwarah, Saudi Arabia \\ ${ }^{6}$ Medical Genetics, Clinical Laboratory Department, College of Applied Medical Sciences, Taif University, Taif, Saudi Arabia \\ ${ }^{7}$ Department of Medical Biochemistry, Faculty of Medicine, Mansoura University, Mansoura, Egypt \\ ${ }^{8}$ Genetics Unit, Histology and Cell Biology Department, Faculty of Medicine, Suez Canal University, Ismailia, Egypt
}

Correspondence should be addressed to Manal S. Fawzy; manal2_khashana@ymail.com

and Eman A. Toraih; emantoraih@gmail.com

Received 2 October 2017; Accepted 11 December 2017; Published 21 March 2018

Academic Editor: Simona G. Bungǎu

Copyright (c) 2018 Manal S. Fawzy et al. This is an open access article distributed under the Creative Commons Attribution License, which permits unrestricted use, distribution, and reproduction in any medium, provided the original work is properly cited.

\begin{abstract}
Glioblastoma multiforme (GBM) (grade IV astrocytoma) has been assumed to be the most fatal type of glioma with low survival and high recurrence rates, even after prompt surgical removal and aggressive courses of treatment. Transcriptional reprogramming to stem cell-like state could explain some of the deregulated molecular signatures in GBM disease. The present study aimed to quantify the expression profiling of longevity-related transcriptional factors SOX2, OCT3/4, and NANOG to evaluate their diagnostic and performance values in high-grade gliomas. Forty-four specimens were obtained from glioblastoma patients (10 females and 34 males). Quantitative real-time polymerase chain reaction was applied for relative gene expression quantification. In silico network analysis was executed. NANOG and OCT3/4 mRNA expression levels were significantly downregulated while that of SOX2 was upregulated in cancer compared to noncancer tissues. Receiver operating characteristic curve analysis showed high diagnostic performance of NANOG and OCT3/4 than SOX2. However, the aberrant expressions of the genes studied were not associated with the prognostic variables in the current population. In conclusion, the current study highlighted the aberrant expression of certain longevity-associated transcription factors in glioblastoma multiforme which may direct the attention towards new strategies in the treatment of such lethal disease.
\end{abstract}

\section{Introduction}

Tumors of the brain were considered one of the ten most common causes of cancer-related mortality [1]. According to the World Health Organization (WHO) classification, the primary brain tumors are categorized into glial tumors (e.g., glioblastoma, astrocytomas, oligodendroglial tumors, and ependymal tumors), embryonic tumors (e.g., medulloblastomas), tumors of the meninges, tumors of the hematopoietic system, and tumors of the sellar region [2]. The most fatal type of glioma has been reported to be the glioblastoma multiforme (GBM) [3] which represents up to $50 \%$ of almost all primary brain gliomas [4] with poor prognosis [5] and median survival rate of nearly 25 months after treatment [6]. The recurrence of the tumor after prompt surgical removal despite the aggressive courses of radio- and chemotherapy denotes the limited understanding of the disease biology [7]. Dell'Albani has stated that "new insights into the causes and the potential treatment of CNS tumors have come from disclosing relations with genes that regulate cell 
growth, proliferation, differentiation, and death during normal development" [7]. These genes may represent a new target for GBM treatment by ameliorating the survival rate and preventing or minimizing disease recurrence.

Several emerging evidences support the reactivation of pluripotent transcription factors in many types of cancer [8-12]. As a normal biological phenomenon, these factors are expressed in embryonic stem cells (ESCs) and somatic cells where they imply the self-renewal [13] and the pluripotency characteristics [14]. As cancer development is a multistep process in which differentiated cells transform into immature ones, these factors could participate in cancer biogenesis and/or progress.

Among these pluripotent transcription factors overexpressed in high-grade gliomas are "sex-determining region Y-Box (SOX2), octamer-binding transcription factor 4 (OCT 4), and Nanog homeobox (NANOG)" [13, 15].

SOX2 gene encodes a transcriptional factor (TF) of 317 amino acids which contains a high-mobility group DNAbinding domain (Figure 1(a)) [16]. It implicated in embryonic development regulation, cell fate determination, and embryonic stem cell pluripotency. More specifically, it was reported to control the neural stem cell proliferation and differentiation into neurons, astrocytes, or oligodendrocytes [17]. SOX2 is expressed in stem cells of endoderm-derived organs such as the liver, pancreas, and stomach [18], and its aberrant expression has been found to support selfrenewal and inhibit neuronal differentiation [19]. Additionally, SOX2 knockout in glioblastoma stem cells isolated from human glioma tumor inhibits cell proliferation and tumorigenicity in immunodeficient mice [20].

OCT3/4 is a member of a transcription POU family (Figure 1(b)) which has to react with other TFs in order to stimulate or inhibit gene expression [21] in ESCs through heterodimerization with SOX2. It was implicated in embryonic development regulation, cell fate determination, and embryonic stem cell pluripotency [22]. Finally, NANOG (Figure 1(c)) is involved in gene regulation with the aforementioned two transcription factors through their binding to the promoters of several genes which mediates the pluripotency, inhibits embryonic stem cell differentiation, and autorepresses its own expression in differentiating cells [22]. It has been found to be localized mainly in the nuclei of high-grade glioma cells than lower grades [15]. Despite the fact that OCT3/4 and NANOG have shown a direct relationship with the tumor grade, their oncogenic nature in brain tumorigenesis has not been established yet [23].

Up to our knowledge, there were no previous studies that relate the expression of the aforementioned longevityrelated transcription factors in GBM patients among the Arab population. Hence, the present study for the first time aimed to quantify the expression levels of these markers in GBM sample of Egyptian patients and to correlate their expressions with the available clincopathological features. A thorough understanding of the relevance of each biomarker in GBM will be in need not only for reliable diagnosis of the disease but also to participate in future drug design for this fetal tumor.

\section{Materials and Methods}

2.1. Study Participants and Tissue Samples. The current study included 44 glioblastoma patients (10 females and 34 males, aged 38 to 62 years) assessed retrospectively from archived formalin-fixed paraffin-embedded section (FFPE) specimens of the Pathology Department, Mansoura University Hospitals, Egypt, from 2010 to 2013. They had glioblastoma multiforme grade 4, subjected to surgical removal and postoperative irradiation, and followed up for more than 36 months. Specimens were collected before receiving chemotherapy or radiotherapy prior to surgery. They were compared to 10 FFPE noncancerous brain specimens obtained from patients undergoing brain tissue resection for other reasons collected from the same hospital. Guidelines in the Declaration of Helsinki were followed, and an approval by the Medical Research Ethics Committee of Faculty of Medicine, Suez Canal University, was obtained before taking part. Written informed consent was obtained from all participants before providing the archived tissue samples as part of their routine register in our University Teaching Hospitals.

2.2. RNA Extraction. Extraction of total RNA from FFPE specimens was done using RNeasy FFPE Kit (Qiagen, 52304) according to the protocol of the manufacturer. RNA concentration and purity were assessed with NanoDrop ND-1000 spectrophotometer (NanoDrop Tech. Inc., Wilmington, DE, USA), followed by agarose gel electrophoresis (1\%) check for RNA integrity.

2.3. Reverse Transcription (RT). Complementary DNA (cDNA) was obtained by total RNA conversion using the High-Capacity cDNA Reverse Transcription Kit (Applied Biosystems, $\mathrm{P} / \mathrm{N}$ 4368814) with $\mathrm{RT}$ random primers on T-Professional Basic, Biometra PCR System (Biometra, Goettingen, Germany), as previously described [12]. Appropriate negative and positive controls were included in each experiment.

2.4. Gene Expression Profiling. The Minimum Information for Publication of Quantitative Real-Time PCR Experiments (MIQE) guidelines were followed for the real-time PCR reactions. Pluripotent gene relative expressions were assessed using "Universal PCR master mix II, No UNG $(2 \times)$ " (TaqMan ${ }^{\circledR}$, Applied Biosystems, P/N 4440043), TaqMan assay (Applied Biosystems, assay ID Hs02387400_g1 for NANOG, Hs01053049_s1 for SOX2, and Hs03005111_g for OCT3/4) and compared to the endogenous control TATA box binding protein (TBP) (Hs00427620_m1) which has been proved in our previous work [24] to be uniformly and stably expressed with no significant difference between GBM and noncancer tissues for gene expression normalization. PCRs were done in $20 \mu \mathrm{l}$ total volume using "StepOne ${ }^{\mathrm{TM}}$ Real-Time PCR System (Applied Biosystems)" as previously described in details [25].

2.5. Statistical Analysis. Data analysis was done using PCORD ver. 5 software package and Statistical Package for the Social Sciences (SPSS) for windows software (version 22.0). Two-tailed statistical tests were used for continuous and 


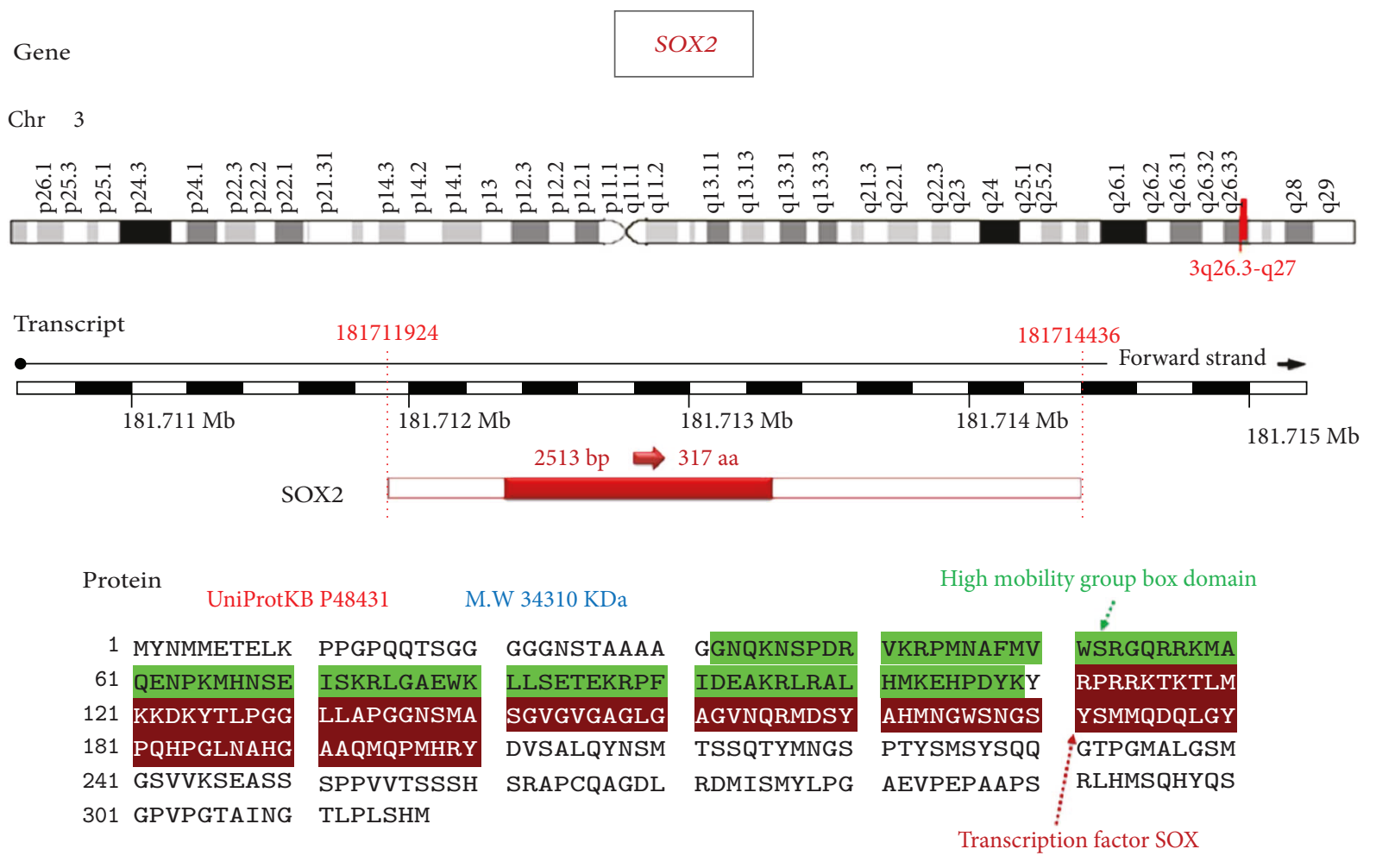

(a)

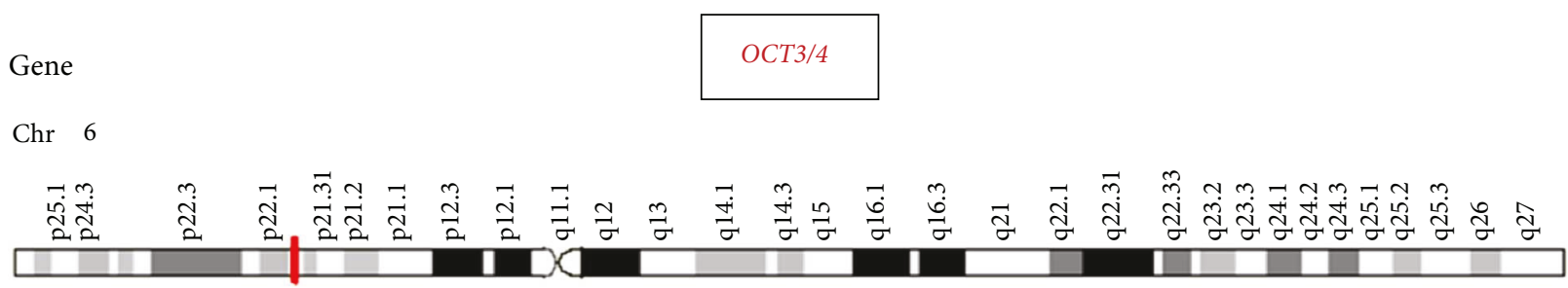

$6 \mathrm{p} 21.33$

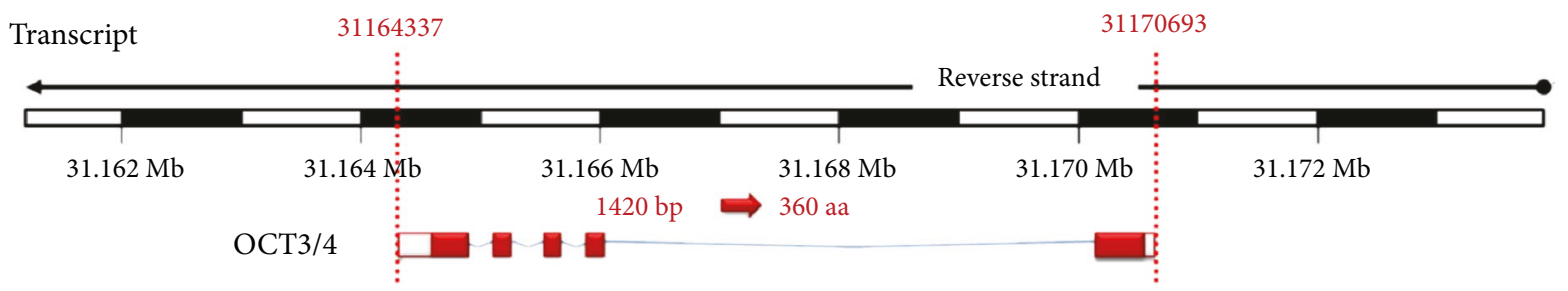

Protein

Protein UniProtKB Q01860 MW 38,571 Da

POU-specific domain

1 MAGHLASDFA FSPPPGGGGD GPGGPEPGWV DPRTWLSFQG PPGGPGIGPG VGPGSEVWGI

61 PPCPPPYEFC GGMAYCGPQV GVGLVPQGGL ETSQPEGEAG VGVESNSDGA SPEPCTVTPG

121 AVKLEKEKLE QNPEESQDIK ALQKELEQFA KLLKQKRITL GYTQADVGLT LGVLFGKVFS

181 QTTICRFEAL QLSFKNMCKL RPLLQKWVEE ADNNENLQEI CKAETLVQAR KRKRTSIENR

241 VRGNLENLFL QCPKPTLQQI SHIAQQLGLE KDVVRVWFCN RRQKGKRSSS DYAQREDFEA

301 AGSPFSGGPV SFPLAPGPHF GTPGYGSPHF: TALYSSVPFP EGEAFPPVSV TTLGSPMHSN

DNA-binding domain $230-289$

(b)

FIgURe 1: Continued. 


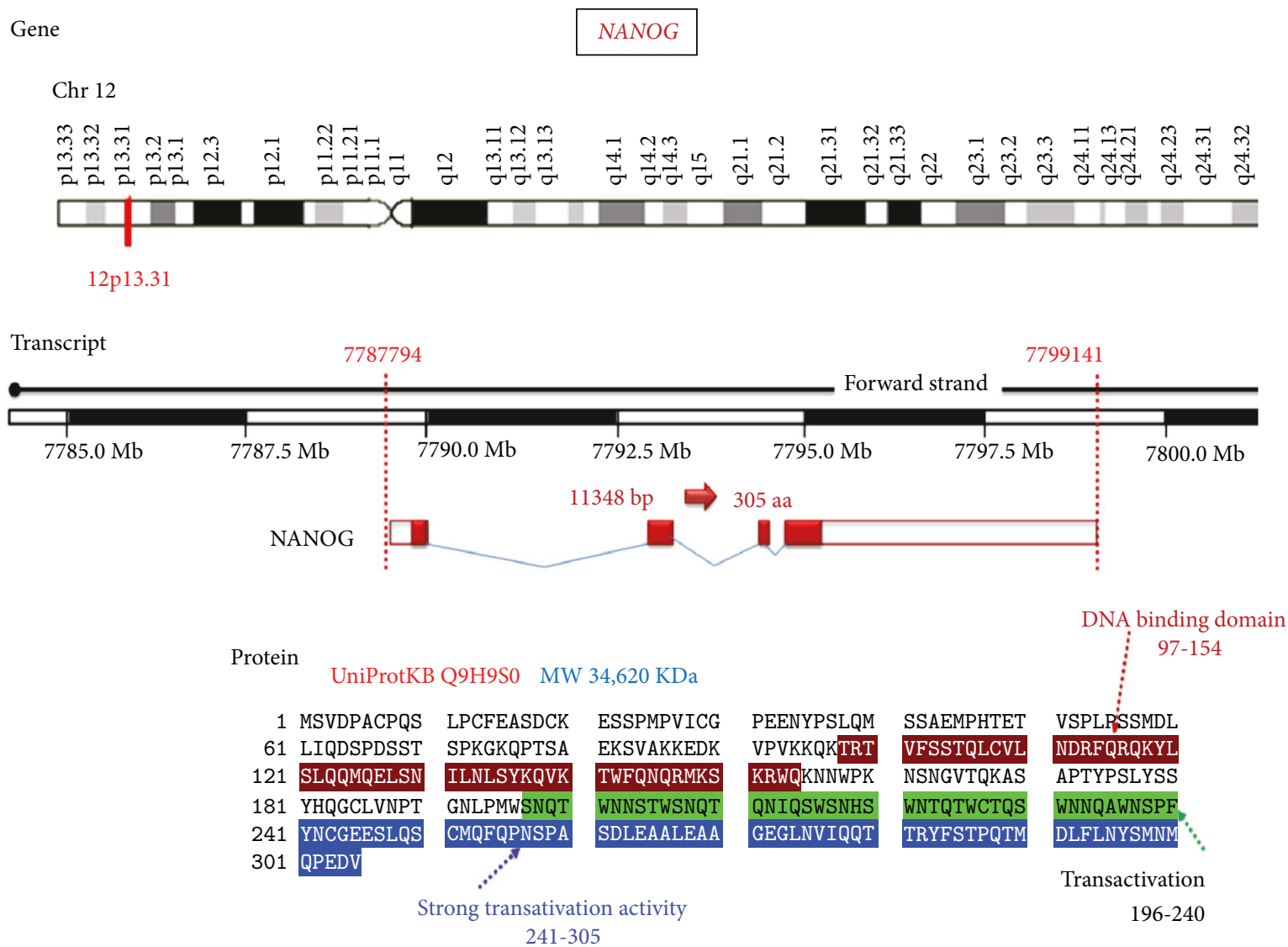

(c)

FIGURE 1: Structural analysis of the studied longevity-related genes. (a) SOX2 gene (OMIM 184429) location in chromosome 3q26.33. The complete gene spans 2513 bases of genomic DNA (NC_000003.12; Chr 3: 181,711,924 to 181,714,436, plus strand; human genome assembly GRCh38). This intronless gene encodes a member of the SRY-related HMG-box family of transcription factors (translation length: 317 amino acids). SOX2 refers to the primary and predominant transcript of the SOX2 gene. The high-mobility group box domain amino acid sequence in the SOX2 transcription factor is highlighted by green color and the DNA-binding domain sequences are brown colored. (b) NANOG gene (OMIM: 607937) location in chromosome 12p13.31. The complete gene spans 11,348 bases of genomic DNA (NC_000012.12; Chr 12: 7,787,794 to 7,799,141, plus strand). The encoded protein (305 amino acids). (c) OCT3/4 gene (OMIM: 164177) location in chromosome 6p21.33. The gene spans 1420 bases of genomic DNA (NC_00006.12; genomic coordinates (GRCh38): 6: 31,164,337-31,170,693, minus strand). The gene encodes a transcription factor (360 amino acids) containing a POU-specific homeodomain (blue amino acid sequences) and DNA-binding domain (brown amino acid sequences). MW: molecular weight; Da: Dalton; aa: amino acids (data source: http://Genecards.org, http://Ensembl.org and UniProtKB).

categorical variables. Correlation analysis between the variables was performed via Pearson's correlation coefficient. $p$ value $<0.05$ was considered significant. The fold change of mRNA expression in each patient cancer tissue relative to the mean of controls was calculated using Livak method that depends on the quantitation cycle $\left(C_{\mathrm{q}}\right)$ value with the following equation: relative quantity $=2^{-\Delta \Delta C_{\mathrm{q}}}$ [26]. The diagnostic performance of pluripotent genes was evaluated by receiver operating characteristic (ROC) analysis. KaplanMeier estimator was generated for survival analysis, and log-rank test was applied for different Kaplan-Meier curve (stratified by clinicopathological features) comparisons. Linear regression analysis using ENTER method was performed to evaluate potential factors affecting the overall survival of patients. Two-way Hierarchical cluster analysis was run for exploratory multivariate analysis. Ward's method and Euclidean (Pythagorean) were adjusted for linkage method and distance measure, respectively, with a beta value of -0.75 to reach the minimum \% of chaining. Principal Component Ordination analysis was used to visualize clustering of patients according to their clinicopathological characteristics [27].

\section{Results}

3.1. Expression Profile of Pluripotent Genes. Baseline clinical features of the study participants are illustrated in Table 1. Relative expression analyses of pluripotent genes in brain cancer specimens were compared to TBP. Our results revealed that the expression levels of $N A N O G$ and OCT3/4 were significantly downregulated $(p<0.001$ and $=0.001$, resp.) while that of SOX2 was significantly upregulated $(p=0.0027)$ in tumor specimens compared to noncancer tissues (Figures 2(a) and 2(b)). Both NANOG 
TABLE 1: Characteristics of GBM patients.

\begin{tabular}{|c|c|}
\hline Variables & Number $(\%)$ or mean $\pm \mathrm{SE}$ \\
\hline \multicolumn{2}{|l|}{ Age } \\
\hline Mean \pm SE & $51.4 \pm 0.97$ \\
\hline \multicolumn{2}{|l|}{ Age categories } \\
\hline $35-50 y$ & $18(40.9)$ \\
\hline$>50 y$ & $26(59.1)$ \\
\hline \multicolumn{2}{|l|}{ Gender } \\
\hline Female & $10(22.7)$ \\
\hline Male & $34(77.3)$ \\
\hline \multicolumn{2}{|l|}{ Tumor site } \\
\hline Frontal & $22(50)$ \\
\hline Frontotemporal & $4(9.1)$ \\
\hline Temporoparietal & $18(40.9)$ \\
\hline \multicolumn{2}{|l|}{ Recurrence } \\
\hline Nonrecurrent & $36(81.8)$ \\
\hline Recurrent & $8(18.2)$ \\
\hline \multicolumn{2}{|c|}{ Disease-free survival (months) } \\
\hline Mean \pm SE & $15.1 \pm 0.85$ \\
\hline Range & $6-27$ \\
\hline Prolonged DFS (>1 y) & $28(63.6)$ \\
\hline Short DFS ( $\leq 1 \mathrm{y})$ & $16(36.4)$ \\
\hline \multicolumn{2}{|c|}{ Overall survival (months) } \\
\hline Mean \pm SE & $15.6 \pm 0.86$ \\
\hline Range & $8-27$ \\
\hline High survival (>1 y) & $30(68.2)$ \\
\hline Low survival ( $\leq 1 \mathrm{y})$ & $14(31.8)$ \\
\hline
\end{tabular}

and OCT3/4 mRNAs showed high diagnostic values as biomarkers for GBM (AUC $=0.886 \pm 0.054$ and 0.736 \pm 0.078 , resp.) (Figure 3).

3.2. Association with Clinicopathological Characteristics and Survival Analysis. Higher OCT3/4 gene expression was noted in elder GBM patients $(p=0.036)$. No statistically significant association was found with any other parameters (Figure 4). Correlation analysis revealed moderate correlation between NANOG and SOX2 gene expression profile $(r=0.484, p=$ $0.023)$. In addition, elder age of patients was associated with poor overall survival (OS) $(r=-0.479, p=0.024)$ and disease-free survival (DFS) $(r=-0.481, p=0.023)$ (Figure 5).

Linear regression analysis was performed to evaluate potential factors affecting overall survival of patients. None of the genes or clinicopathological variables was determined as a good prognostic marker for patients' survival in the study population (Table 2). However, survival analysis in GBM by log-rank and Tarone-Ware tests showed poor OS among elder patients (Figure 6 and Table S1).

3.3. Multivariate Analysis. Exploratory multivariate analysis by principle component and hierarchical cluster analyses classified patients into 3 groups based on the relative expression of the combined genes (Figure 7). However, there was no

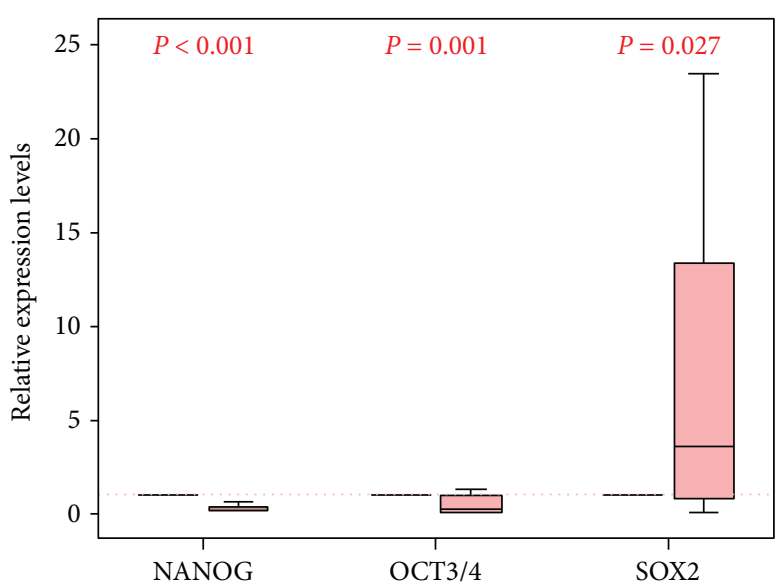

(a)

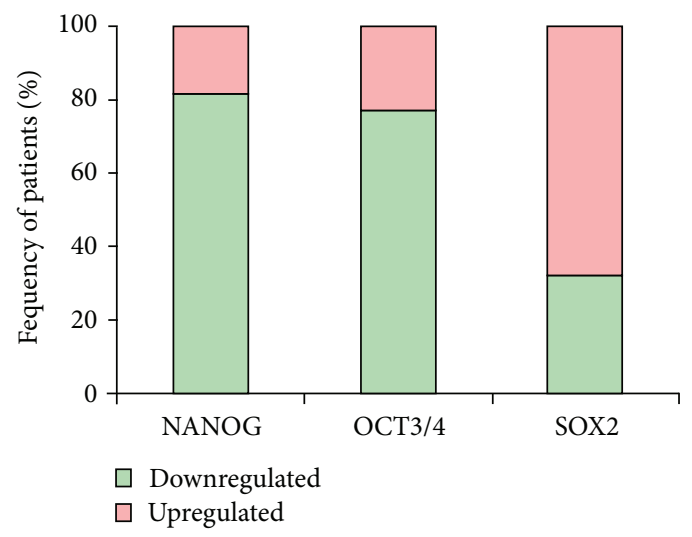

(b)

FIGURE 2: Expression profile of pluripotent genes in GBM patients compared to controls. (a) Values are presented as medians and quartiles of fold change relative to controls. The box defines upper and lower quartiles (25\% and $75 \%$, resp.) and the Whisker bars indicate upper and lower adjacent limits. TBP was used as an internal control. Noncancer tissues was set to have a relative expression value of 1.0. Mann-Whitney $U$ test was used for comparison. $p$ value $<0.05$ was considered statistically significant. (b) Frequency of patients with up- and downregulated genes.

clear demarcation found between patients according to age, gender, tumor site, and recurrence (Figure S1).

\section{Discussion}

The presence of a significant heterogeneity in certain types of solid tumors including GBM is becoming obvious. Hence, it will be rational to search for and evaluate specific molecular markers that could assist in diagnosis and/or prognosis of these tumors and could act as targeted molecular markers for personalized therapy [7]. Here, we attempted to investigate the presence of a molecular signature of longevityrelated genes (SOX2, NANOG, and OCT3/4) by examining their mRNA expression in GBM tissues relative to noncancer tissues. Our analyses revealed that the expression level of SOX2 was significantly upregulated. This finding was consistent with several independent cohorts [28-30] and in part with Guo et al., [13] who detected an overexpression of 


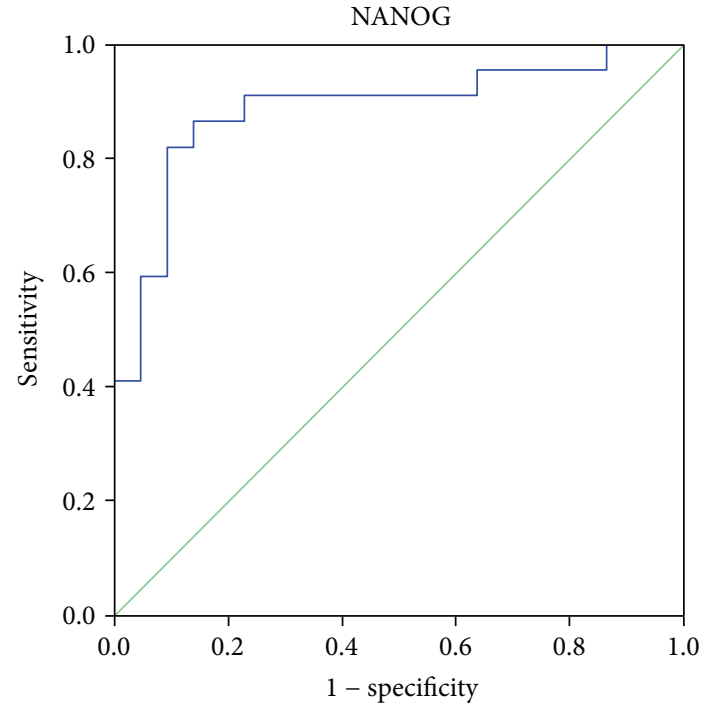

(a)

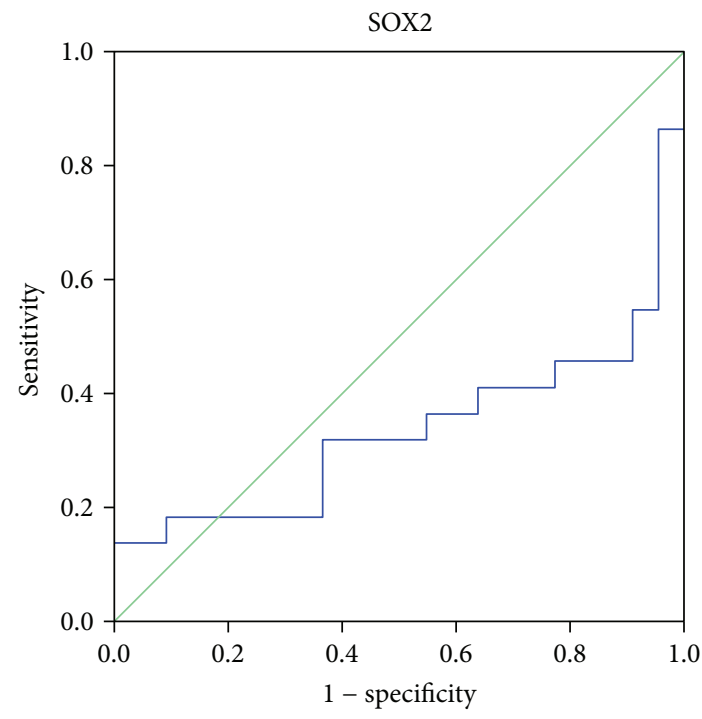

(c)

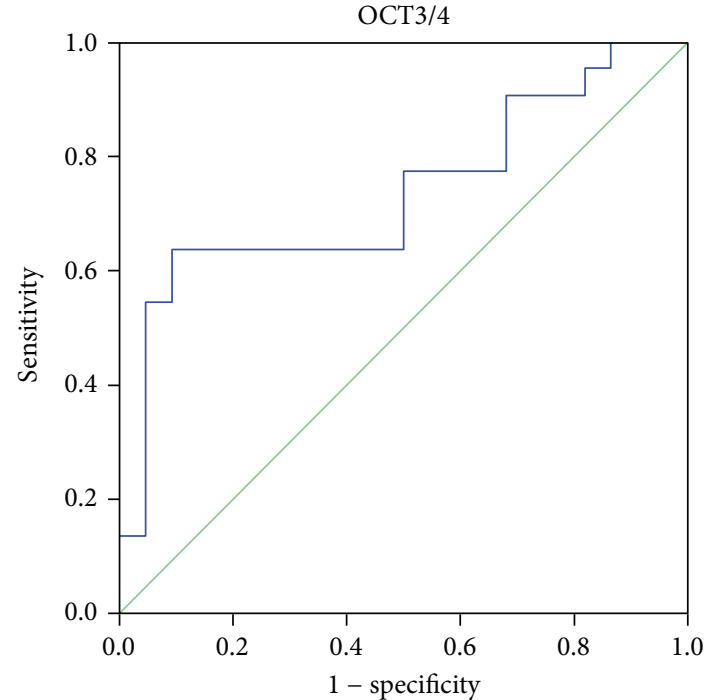

(b)

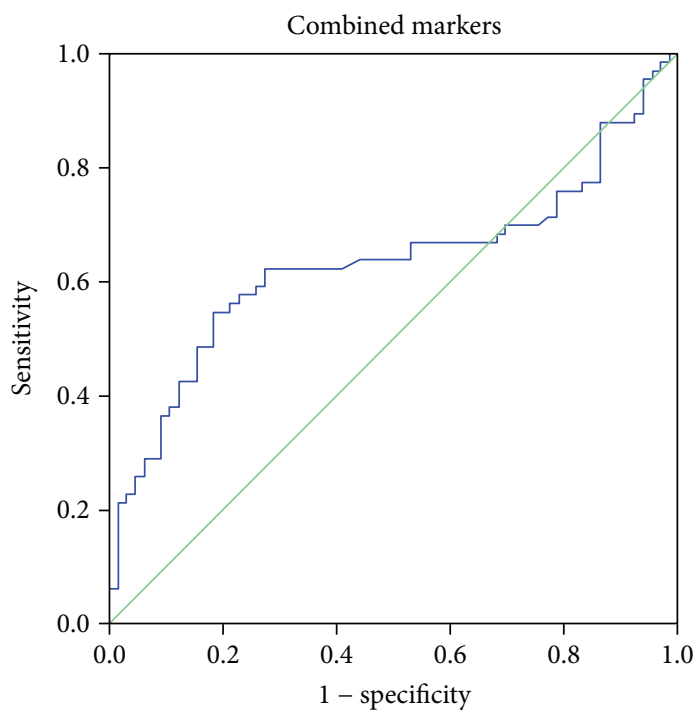

(d)

Area under the curve

\begin{tabular}{lccccc}
\hline Markers & AUC & SE & $P$ values & Lower bound & Upper bound \\
\hline NANOG & 0.886 & 0.054 & 0.000 & 0.780 & 0.992 \\
OCT3/4 & 0.736 & 0.078 & 0.007 & 0.582 & 0.889 \\
SOX2 & 0.335 & 0.087 & 0.060 & 0.164 & 0.505 \\
Combined & 0.631 & 0.051 & 0.009 & 0.531 & 0.731 \\
\hline
\end{tabular}

FIGURE 3: Diagnostic performance of pluripotent genes to discriminate between GBM and noncancer samples. NANOG and OCT3/4 showed high diagnostic values as biomarkers for GBM.

SOX2 mRNA in grade IV gliomas compared to grade II. Of the three longevity-related factors, SOX2 seems to be the playmaker in the development of brain tumors [18]. When overexpressed, it promotes cell cycle progression into $\mathrm{S}$ phase and proliferation $[3,20,28,31]$, which were attenuated by application of SOX2-RNAi (RNA interference) therapy [32]. At the cellular level, Garros-Regulez et al. [33] proposed SOX2 upregulation via activation of GBMspecific signaling pathways that maintain the overexpression of SOX2 via transforming growth factor-beta (TGF- $\beta$ ), Sonic Hedgehog $(\mathrm{SHH})$, epidermal growth factor receptor (EGFR), and fibroblast growth factor receptor (FGFR) 

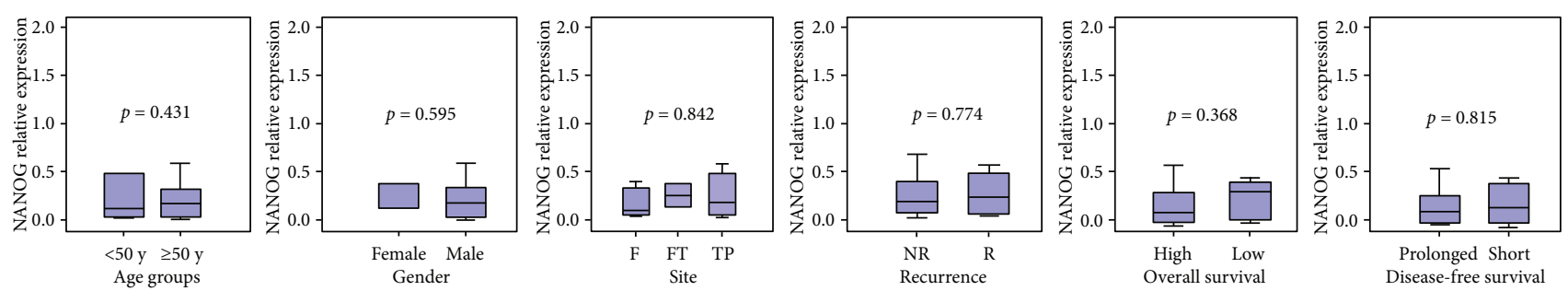

(a)
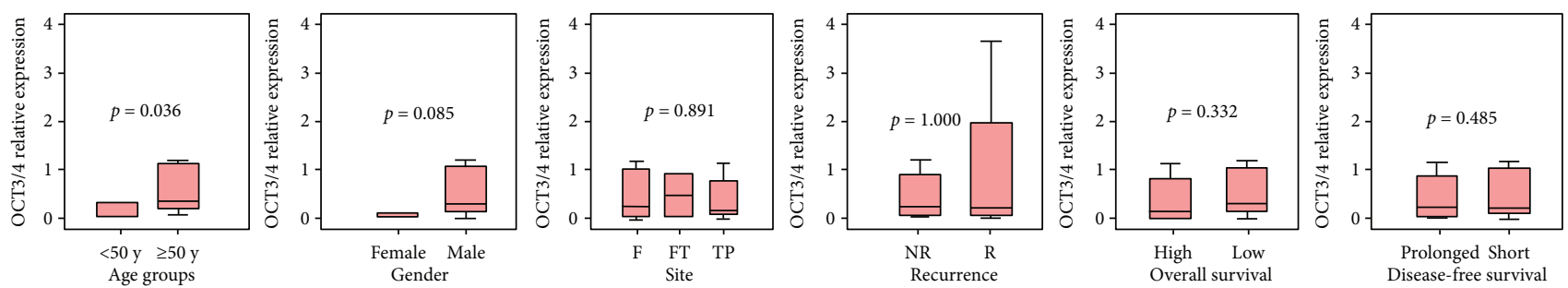

(b)
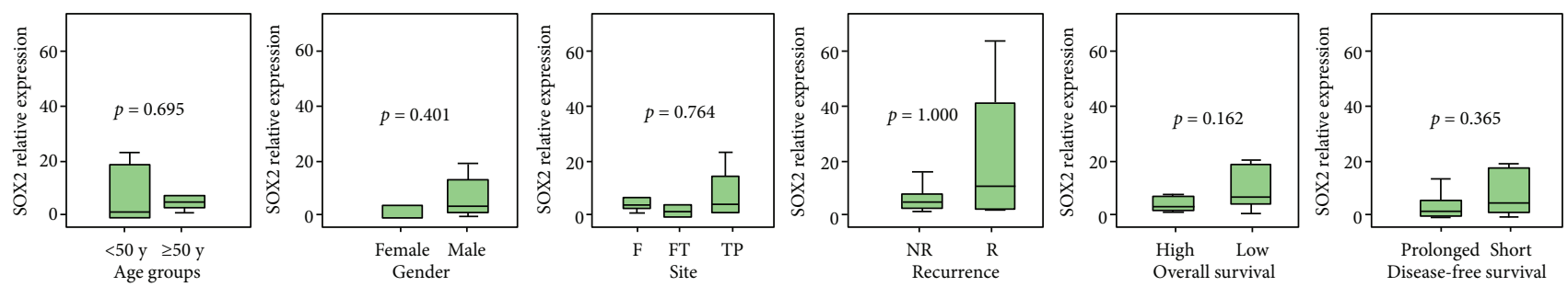

(c)

FIGURE 4: Association between gene expression and the clinicopathological features. Values are presented as medians and quartiles of fold change relative to controls. The box defines upper and lower quartiles (25\% and $75 \%$, resp.) and the whisker bars indicate upper and lower adjacent limits. TBP was used as an internal control. Noncancer tissues were set to have a relative expression value of 1.0. Mann-Whitney $U$ and Kruskal-Wallis tests were used for comparison. $p$ value $<0.05$ was considered statistically significant. F: frontal tumor site; FT: frontotemporal; TP: temporoparietal; R: recurrent; NR: nonrecurrent.

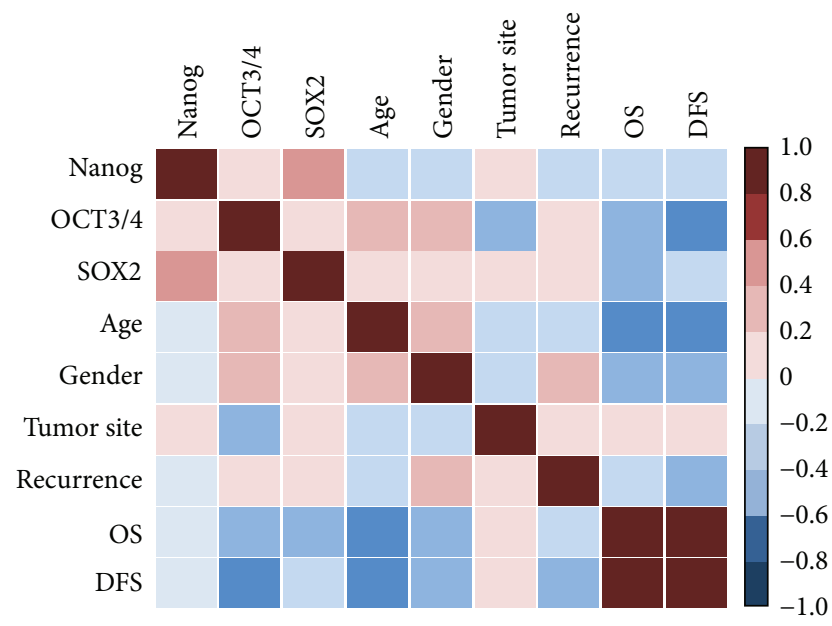

FIgURE 5: Correlation matrix between transcriptomic signature and the clinicopathological features. Pearson's correlation analysis was performed and represented as color gradient.

pathways. In addition, SOX2 gene amplification and DNA promoter hypomethylation have been reported in a group of GBM patients to expand the mechanism responsible for SOX2 upregulation [34].
Despite that our in silico analysis revealed that the expression of the studied stem-related factors has similar colocalization and physical interactions with each other [12], they seem to be differentially expressed independently in the current samples. We found that NANOG and OCT3/ 4 were significantly downregulated in GBM tissues. Our finding might seem contradictory to the stemness role these pluripotent transcription factors play; however, it is worth to emphasize that the mechanistic functions of SOX2, OCT4, and NANOG in cancer cells are a little different in each stage of tumor progress. Kallas et al. reported high levels of SOX2, OCT4, and NANOG transcription factor expressions at the beginning of their tested human embryonic stem cell differentiation. However, on progress of the differentiation process, a decline in OCT4 and NANOG expression levels was observed, while expression of SOX2 was kept at a high level [35]. They suggested that the pluripotency is maintained by a transcriptional network that is harmonized by the aforementioned core transcription factors. During differentiation, the epigenetic modifications could play a role in level modulation of these factors.

The other possible reasons for inconsistency of gene expression for the three stem cell marker studies could be sampling bias and/or relatively low expression levels of these 
TABLE 2: Linear regression analysis to determine predictors for survival.

\begin{tabular}{|c|c|c|c|c|c|c|c|}
\hline & \multicolumn{2}{|c|}{ Unstandardized coefficients } & \multirow{2}{*}{$\begin{array}{l}\text { Standardized coefficients } \\
\text { Beta }\end{array}$} & \multirow[b]{2}{*}{$t$} & \multirow[b]{2}{*}{ Sig. } & \multicolumn{2}{|c|}{$95 \%$ confidence interval for $B$} \\
\hline & $B$ & Std. error & & & & Lower bound & Upper bound \\
\hline (Constant) & 34.675 & 10.593 & & 3.273 & 0.006 & 11.955 & 57.395 \\
\hline Age & -0.318 & 0.220 & -0.363 & -1.448 & 0.170 & -0.790 & 0.153 \\
\hline Gender & -2.142 & 3.510 & -0.170 & -0.610 & 0.551 & -9.671 & 5.387 \\
\hline Tumor site & 0.079 & 1.498 & 0.014 & 0.053 & 0.959 & -3.134 & 3.292 \\
\hline Recurrence & 0.501 & 3.635 & 0.036 & 0.138 & 0.892 & -7.295 & 8.296 \\
\hline NANOG & 0.374 & 3.095 & 0.033 & 0.121 & 0.905 & -6.263 & 7.011 \\
\hline ОСТ3/4 & -0.943 & 1.339 & -0.173 & -0.705 & 0.493 & -3.815 & 1.928 \\
\hline SOX 2 & -0.085 & 0.123 & -0.214 & -0.691 & 0.501 & -0.348 & 0.178 \\
\hline
\end{tabular}

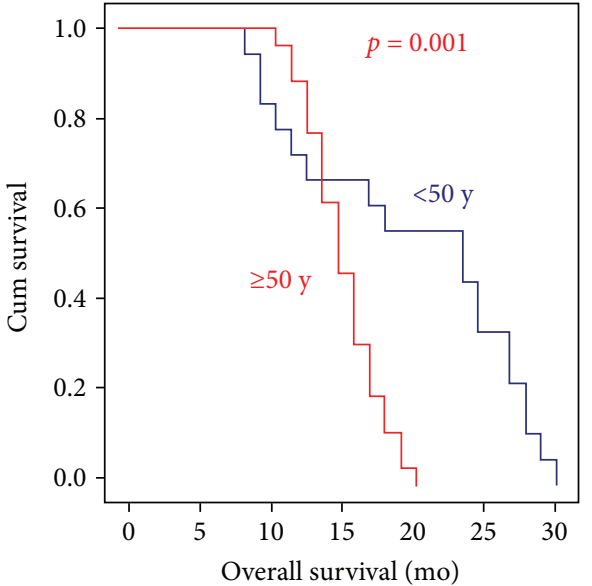

(a)

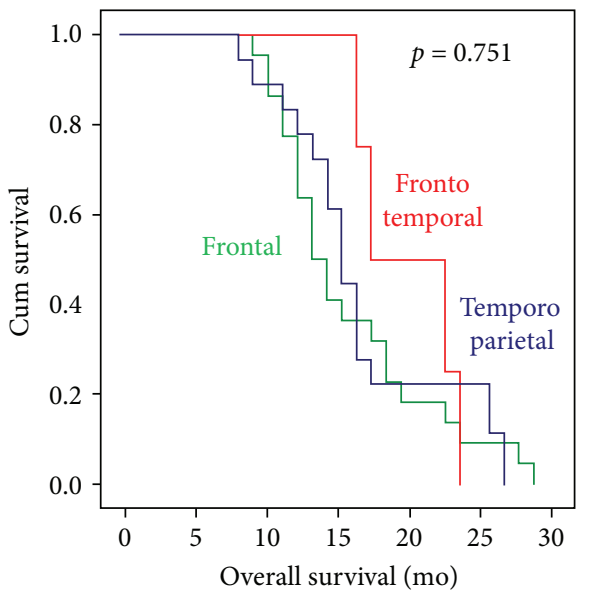

(c)

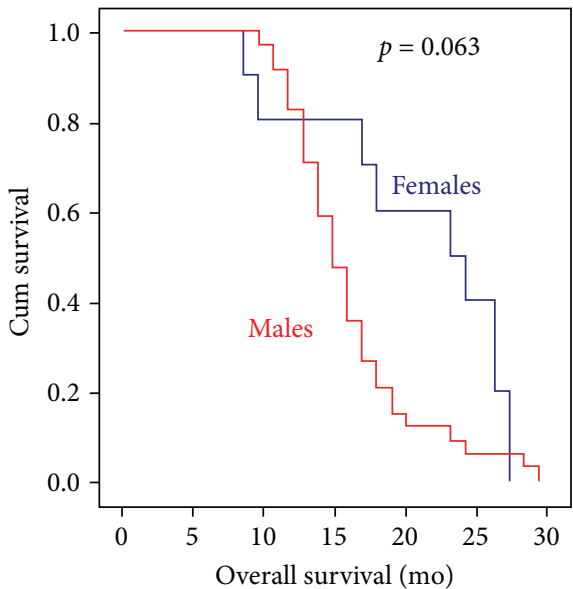

(b)

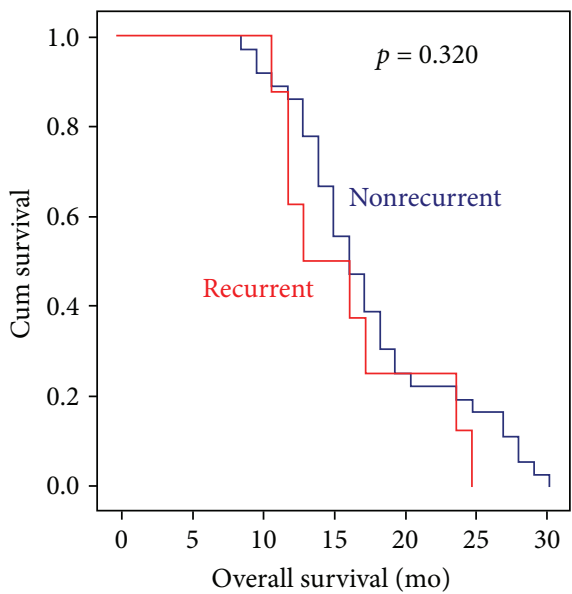

(d)

Figure 6: Kaplan-Meier survival curve in GBM patients. Log-rank (Mantel-Cox) test was used for comparison. Statistical significance at $p<0.05$.

factors within the individual GBM tissue examined in the current study [36]. This could be explained by the unique stem cell signature that has been implied by each tumor due to the inherent intratumor heterogeneity within GBM tissues [37-39]. Our multivariate analysis and the hierarchical cluster analysis confirmed the previous suggestions by revealing classification of the study population into 3 groups based on the combined gene expression that confirm a specific protumorigenic profile. Similar to other combinations of cancer stem cell markers in other types of cancer $[40,41]$, previous studies revealed that cancer stem cells which were isolated using different markers in the same 


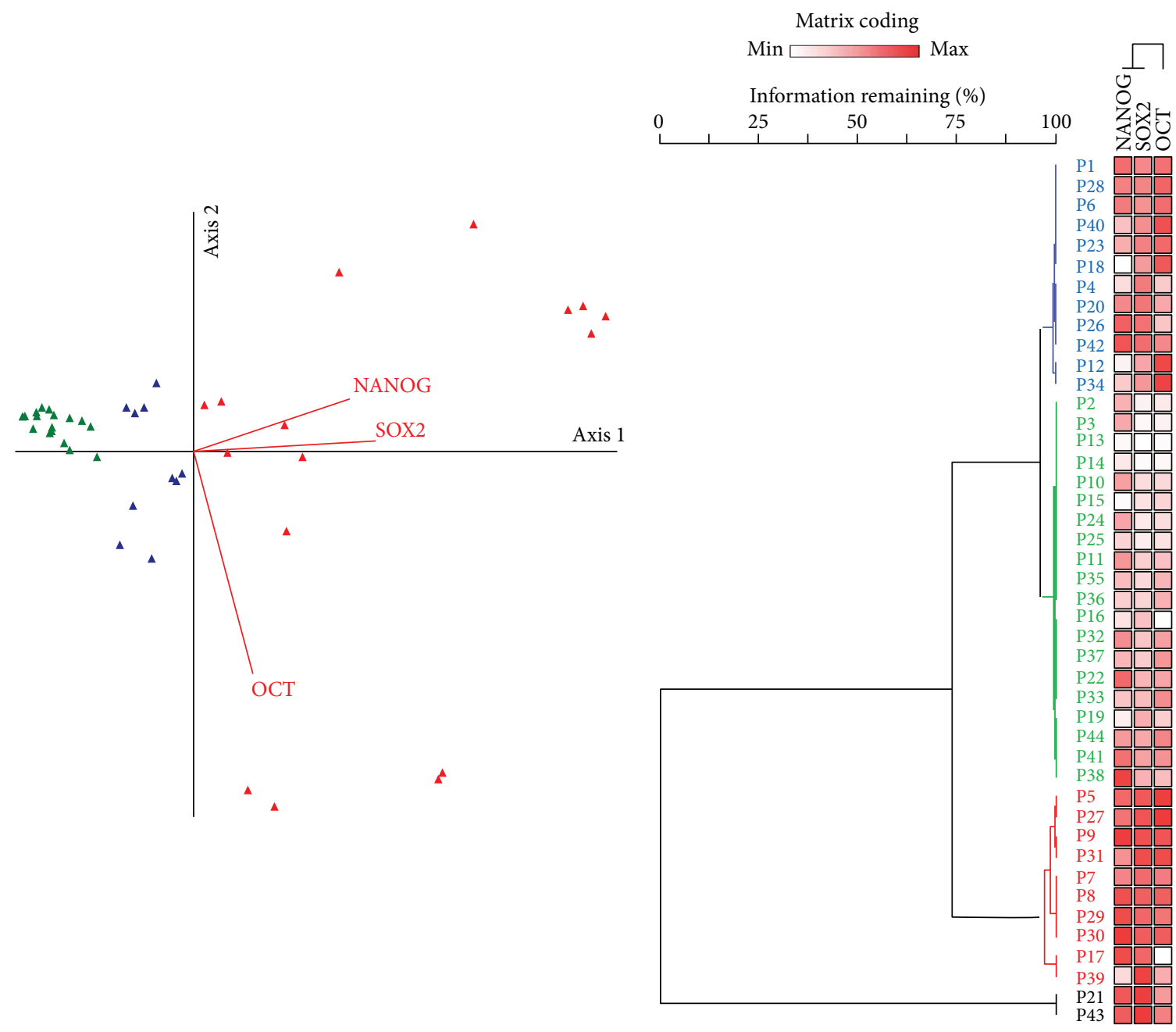

(a)

(b)

FIGURE 7: Multivariate analyses cluster GBM patients according to transcriptomic signature. PC-ORD v5.0 was used for exploratory multivariate analysis. Data set was profiled by the program. There was no need for transformation as beta diversity was zero and there was no outlier. (a) Ordination graph by PCO and (b) two-way hierarchical cluster analysis. The following parameters were adjusted: linkage method; Ward's method; distance method; Euclidean method; relativizing matrix by column maximum; and matrix coding percentile by column. Percent chaining =7.38. Clustering identified three patient groups according to their gene expression. The red clade for overexpression of the three pluripotent genes, the green clade discriminates patients with gene downregulation, and the blue clade has variable degrees of expression. Two samples (black clade) were out-group from the other clusters.

cancer phenotype had different expression profiles quantified by real-time PCR. Combined expression analysis might more accurately identify true cancer stem cells for each type of cancer [40], including GBM tumors.

Ji et al. reported that unlike normal stem cells, OCT4 could be dispensable for self-renewal, survival, and differentiation of transformed cells. They provided direct evidence for the functional divergence of OCT4 from the pluripotent state following the cancer tissue transformation [42]. This could support the downregulation of this stem-related marker noted in the current advanced stages of GBM cases. Additionally, Bradshaw et al. [36] reported low OCT4 relative expressions at the transcription and protein levels within their FFPE GBM samples. They speculated that the relatively OCT4-expressing cell low number could indicate the most primitive stem cell population within GBM which may possibly bring about the rest of downstream cells within the GBM tumor. Otherwise, the SOX2 ubiquitous redundancy is more likely to be expressed in the more differentiated cells reflecting its usefulness as a potential progenitor cell marker within the GBM tissues [36].

In contrast to the finding of Zbinden et al. [43] that NANOG was essential for GBM tumourigenicity in orthotopic xenografts, we found downregulation of this marker in the current GBM samples. We speculated that this difference could be due to either the low NANOG-expressing cell number within the study samples as mentioned above for the OCT4 marker or the type of NANOG transcript that has been quantified by the available quantitative PCR analysis at the time of the current work which preferentially recognized the varying levels of NANOG expression. As NANOG is coded by two genes (i.e., NANOG and NANOGP8) in 
human, it has been found that NANOGP8 is the most abundantly expressed of the two NANOG-encoding genes in GBMs, accounting for more than ninety percent of all NANOG-encoding mRNAs in a number of previously tested cases [43]. However, future lineage analyses will be required for unravelling the high NANOG-expressing cell nature and NANOG expression stability as recommended by the latter researchers.

Correlating the available clincopathological features including the survival data of GBM cases with the gene expression results revealed that poor overall survival and disease-free survival were found significantly among patients as reported by previous studies $[44,45]$. Despite that GBM can occur in individuals of any age according to the previous population-based studies, the median age is nearly above 60 years. Additionally, primary GBMs have been reported to develop commonly in older individuals (mean, 55 years), whereas secondary ones were found in middle-aged subjects (39 year olds) [4].

\section{Conclusion}

The current study findings highlighted the dysregulated longevity-related gene expression in GBM Egyptian cases that could have a potential role in carcinogenesis and procuration of stemness-like properties in this type of tumors. The current study could be limited by the relatively small sample size and the fact that all patients have grade IV gliomas, although this last issue increases the specificity of the study results that confined to one stage of GBM. Additional large-scale studies including different glioma grades are recommended to evaluate the relation of the studied longevity-related gene expression with different WHO grades as well as to confirm their putative role as diagnostic and/or prognostic biomarkers. These could be an interesting era for future individualized molecular-targeted therapy for GBM patients.

\section{Abbreviations}

$\begin{array}{ll}C_{\mathrm{q}}: & \text { Quantitation cycle } \\ \text { DFS: } & \text { Disease-free survival } \\ \text { ESCs: } & \text { Embryonic stem cells } \\ \text { GBM: } & \text { Glioblastoma multiforme } \\ \text { MIQE: } & \text { Minimum Information for Publication of } \\ & \text { Quantitative Real-Time PCR Experiments } \\ \text { NANOG: } & \text { Nanog homeobox } \\ \text { OCT: } & \text { Octamer-binding transcription factor } \\ \text { OS: } & \text { Overall survival } \\ \text { ROC: } & \text { Receiver-operating characteristic } \\ \text { RT: } & \text { Reverse transcription } \\ \text { SOX2: } & \text { Sex-determining region Y-Box. }\end{array}$

\section{Conflicts of Interest}

The authors declare that they have no competing of interests.

\section{Acknowledgments}

The authors thank the Oncology Diagnostic Unit and the Center of Excellence in Molecular and Cellular Medicine, Suez Canal University, Ismailia, Egypt, for providing the facilities for performing the research work.

\section{Supplementary Materials}

Table S1: Kaplan-Meier curves comparing survival of patients with different clinical variables. Figure S1: multivariate analysis stratified by clinicopathological features. (Supplementary Materials)

\section{References}

[1] American Cancer Society, Cancer Facts \& Figures 2015, American Cancer Society, Atlanta, 2015.

[2] D. N. Louis, A. Perry, G. Reifenberger et al., "The 2016 World Health Organization classification of tumors of the central nervous system: a summary," Acta Neuropathologica, vol. 131, no. 6, pp. 803-820, 2016.

[3] M. Schmitz, A. Temme, V. Senner et al., "Identification of SOX2 as a novel glioma-associated antigen and potential target for T cell-based immunotherapy," British Journal of Cancer, vol. 96, no. 8, pp. 1293-1301, 2007.

[4] X. Zhang, W. Zhang, W.-D. Cao, G. Cheng, and Y.-Q. Zhang, "Glioblastoma multiforme: molecular characterization and current treatment strategy (review)," Experimental and Therapeutic Medicine, vol. 3, no. 1, pp. 9-14, 2012.

[5] R. Stupp, W. P. Mason, M. J. van den Bent et al., "Radiotherapy plus concomitant and adjuvant temozolomide for glioblastoma," The New England Journal of Medicine, vol. 352, no. 10, pp. 987-996, 2005.

[6] R. R. Lonser, S. Walbridge, A. O. Vortmeyer et al., "Induction of glioblastoma multiforme in nonhuman primates after therapeutic doses of fractionated whole-brain radiation therapy," Journal of Neurosurgery, vol. 97, no. 6, pp. 1378-1389, 2002.

[7] P. Dell'Albani, "Stem cell markers in gliomas," Neurochemical Research, vol. 33, no. 12, pp. 2407-2415, 2008.

[8] I. Ben-Porath, M. W. Thomson, V. J. Carey et al., "An embryonic stem cell-like gene expression signature in poorly differentiated aggressive human tumors," Nature Genetics, vol. 40, no. 5, pp. 499-507, 2008.

[9] M. Schoenhals, A. Kassambara, J. De Vos, D. Hose, J. Moreaux, and B. Klein, "Embryonic stem cell markers expression in cancers," Biochemical and Biophysical Research Communications, vol. 383, no. 2, pp. 157-162, 2009.

[10] J. Matsuoka, M. Yashiro, K. Sakurai et al., "Role of the stemness factors Sox2, Oct3/4, and Nanog in gastric carcinoma," Journal of Surgical Research, vol. 174, no. 1, pp. 130-135, 2012.

[11] W. Luo, S. Li, B. Peng, Y. Ye, X. Deng, and K. Yao, "Embryonic stem cells markers SOX2, OCT4 and Nanog expression and their correlations with epithelial-mesenchymal transition in nasopharyngeal carcinoma," PLoS One, vol. 8, no. 2, article e56324, 2013.

[12] E. A. Toraih, M. S. Fawzy, A. I. El-Falouji et al., "Stemnessrelated transcriptional factors and homing gene expression profiles in hepatic differentiation and cancer," Molecular Medicine, vol. 22, no. 1, pp. 653-663, 2016. 
[13] Y. Guo, S. Liu, P. Wang, S. Zhao, F. Wang, and L. Bing, "Expression profile of embryonic stem cell-associated genes Oct4, Sox2 and Nanog in human gliomas," Histopathology, vol. 59, no. 4, pp. 763-775, 2011.

[14] T. Seymour, A. J. Twigger, and F. Kakulas, "Pluripotency genes and their functions in the normal and aberrant breast and brain," International Journal of Molecular Sciences, vol. 16, no. 11, pp. 27288-27301, 2015.

[15] C. S. Niu, D. X. Li, Y. H. Liu, X. M. Fu, S. F. Tang, and J. Li, "Expression of NANOG in human gliomas and its relationship with undifferentiated glioma cells," Oncology Reports, vol. 26, no. 3, pp. 593-601, 2011.

[16] F. Doetsch, L. Petreanu, I. Caille, J. M. Garcia-Verdugo, and A. Alvarez-Buylla, "EGF converts transit-amplifying neurogenic precursors in the adult brain into multipotent stem cells," Neuron, vol. 36, no. 6, pp. 1021-1034, 2002.

[17] D. Maric, A. Fiorio Pla, Y. H. Chang, and J. L. Barker, "Selfrenewing and differentiating properties of cortical neural stem cells are selectively regulated by basic fibroblast growth factor (FGF) signaling via specific fgf receptors," The Journal of Neuroscience, vol. 27, no. 8, pp. 1836-1852, 2007.

[18] R. Favaro, I. Appolloni, S. Pellegatta, A. B. Sanga, P. Pagella, and E. Gambini, "Sox2 is required to maintain cancer stem cells in a mouse model of high-grade oligodendroglioma," Cancer Research, vol. 74, no. 6, pp. 1833-1844, 2014.

[19] G. Thiel, "How Sox 2 maintains neural stem cell identity," Biochemical Journal, vol. 450, no. 3, pp. e1-e2, 2013.

[20] R. M. Gangemi, F. Griffero, D. Marubbi et al., "SOX2 silencing in glioblastoma tumor-initiating cells causes stop of proliferation and loss of tumorigenicity," Stem Cells, vol. 27, no. 1, pp. 40-48, 2009.

[21] M. Pesce and H. R. Scholer, "Oct-4: gatekeeper in the beginnings of mammalian development," Stem Cells, vol. 19, no. 4, pp. 271-278, 2001.

[22] L. A. Boyer, T. I. Lee, M. F. Cole, S. E. Johnstone, S. S. Levine, and J. P. Zucker, "Core transcriptional regulatory circuitry in human embryonic stem cells," Cell, vol. 122, no. 6, pp. 947956, 2005.

[23] T. Seymour, A. Nowak, and F. Kakulas, "Targeting aggressive cancer stem cells in glioblastoma," Frontiers in Oncology, vol. 5, no. 159, 2015.

[24] M. S. Fawzy, E. A. Toraih, and H. Y. Abdallah, "Long noncoding RNA metastasis-associated lung adenocarcinoma transcript 1 (MALAT1): a molecular predictor of poor survival in glioblastoma multiforme in Egyptian patients," Egyptian Journal of Medical Human Genetics, vol. 18, no. 3, pp. 231239, 2017.

[25] E. A. Toraih, M. S. Fawzy, E. A. Mohammed, M. H. Hussein, and M. M. EL-Labban, "MicroRNA-196a2 biomarker and targetome network analysis in solid tumors," Molecular Diagnosis \& Therapy, vol. 20, no. 6, pp. 559-577, 2016.

[26] K. J. Livak and T. D. Schmittgen, "Analysis of relative gene expression data using real-time quantitative PCR and the $2_{T}^{-\Delta \Delta C}$ method," Methods, vol. 25, no. 4, pp. 402-408, 2001.

[27] M. S. Fawzy, E. A. Toraih, N. M. Aly, A. Fakhr-Eldeen, D. I. Badran, and M. H. Hussein, "Atherosclerotic and thrombotic genetic and environmental determinants in Egyptian coronary artery disease patients: a pilot study," BMC Cardiovascular Disorders, vol. 17, no. 1, p. 26, 2017.

[28] L. Annovazzi, M. Mellai, V. Caldera, G. Valente, and D. Schiffer, "SOX2 expression and amplification in gliomas and glioma cell lines," Cancer Genomics \& Proteomics, vol. 8, no. 3, pp. 139-147, 2011.

[29] C. W. Brennan, R. G. Verhaak, A. McKenna et al., "The somatic genomic landscape of glioblastoma," Cell, vol. 155, no. 2, pp. 462-477, 2013.

[30] A. M. de la Rocha, N. Sampron, M. M. Alonso, and A. Matheu, "Role of SOX family of transcription factors in central nervous system tumors," American Journal of Cancer Research, vol. 4, no. 4, pp. 312-324, 2014.

[31] K. Weina and J. Utikal, "SOX2 and cancer: current research and its implications in the clinic," Clinical and Translational Medicine, vol. 3, no. 1, p. 19, 2014.

[32] F. Oppel, N. Müller, G. Schackert et al., "SOX2-RNAi attenuates S-phase entry and induces RhoA-dependent switch to protease-independent amoeboid migration in human glioma cells," Molecular Cancer, vol. 10, no. 1, p. 137, 2011.

[33] L. Garros-Regulez, I. Garcia, E. Carrasco-Garcia et al., "Targeting SOX2 as a therapeutic strategy in glioblastoma," Frontiers in Oncology, vol. 6, no. 222, 2016.

[34] M. M. Alonso, R. Diez-Valle, L. Manterola et al., "Genetic and epigenetic modifications of Sox 2 contribute to the invasive phenotype of malignant gliomas," PLoS One, vol. 6, no. 11, article e26740, 2011.

[35] A. Kallas, M. Pook, A. Trei, and T. Maimets, "SOX2 is regulated differently from NANOG and OCT4 in human embryonic stem cells during early differentiation initiated with sodium butyrate," Stem Cells International, vol. 2014, Article ID 298163, 12 pages, 2014.

[36] A. Bradshaw, A. Wickremsekera, S. T. Tan, L. Peng, P. F. Davis, and T. Itinteang, "Cancer stem cell hierarchy in glioblastoma multiforme," Frontiers in Surgery, vol. 3, 2016.

[37] D. Stieber, A. Golebiewska, L. Evers et al., "Glioblastomas are composed of genetically divergent clones with distinct tumourigenic potential and variable stem cell-associated phenotypes," Acta Neuropathologica, vol. 127, no. 2, pp. $203-$ 219,2014

[38] A. Morokoff, W. Ng, A. Gogos, and A. H. Kaye, "Molecular subtypes, stem cells and heterogeneity: implications for personalised therapy in glioma," Journal of Clinical Neuroscience, vol. 22, no. 8, pp. 1219-1226, 2015.

[39] A. R. Safa, M. R. Saadatzadeh, A. A. Cohen-Gadol, K. E. Pollok, and K. Bijangi-Vishehsaraei, "Glioblastoma stem cells (GSCs) epigenetic plasticity and interconversion between differentiated non-GSCs and GSCs," Genes \& Diseases, vol. 2, no. 2, pp. 152-163, 2015.

[40] J. Skoda, M. Hermanova, T. Loja, P. Nemec, J. Neradil, and P. Karasek, "Co-expression of cancer stem cell markers corresponds to a pro-tumorigenic expression profile in pancreatic adenocarcinoma," PLoS One, vol. 11, no. 7, article e0159255, 2016.

[41] G. S. Wilson, Z. Hu, W. Duan et al., "Efficacy of using cancer stem cell markers in isolating and characterizing liver cancer stem cells," Stem Cells and Development, vol. 22, no. 19, pp. 2655-2664, 2013.

[42] J. Ji, T. E. Werbowetski-Ogilvie, B. Zhong, S.-H. Hong, and M. Bhatia, "Pluripotent transcription factors possess distinct roles in normal versus transformed human stem cells," PLoS One, vol. 4, no. 11, article e8065, 2009.

[43] M. Zbinden, A. Duquet, A. Lorente-Trigos, S.-N. Ngwabyt, I. Borges, and A. Ruiz i Altaba, "NANOG regulates glioma stem cells and is essential in vivo acting in a cross-functional 
network with GLI1 and p53," The EMBO Journal, vol. 29, no. 15, pp. 2659-2674, 2010.

[44] D. Xie, Y. X. Zeng, H. J. Wang et al., "Amplification and overexpression of epidermal growth factor receptor gene in glioblastomas of Chinese patients correlates with patient's age but not with tumor's clinicopathological pathway," Acta Neuropathologica, vol. 110, no. 5, pp. 481-489, 2005.

[45] M. Vand Rajabpour, H. Yahyazadeh, and M. Beheshti, "Prognostic factors and survival of glioblastoma multiform (GBM) in Iranian patients," International Journal of Cancer Management, vol. 10, article e6260, 2017. 


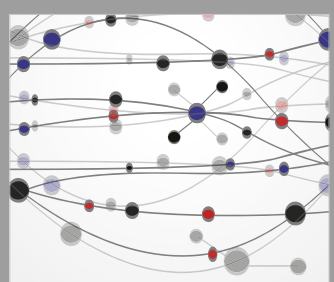

The Scientific World Journal
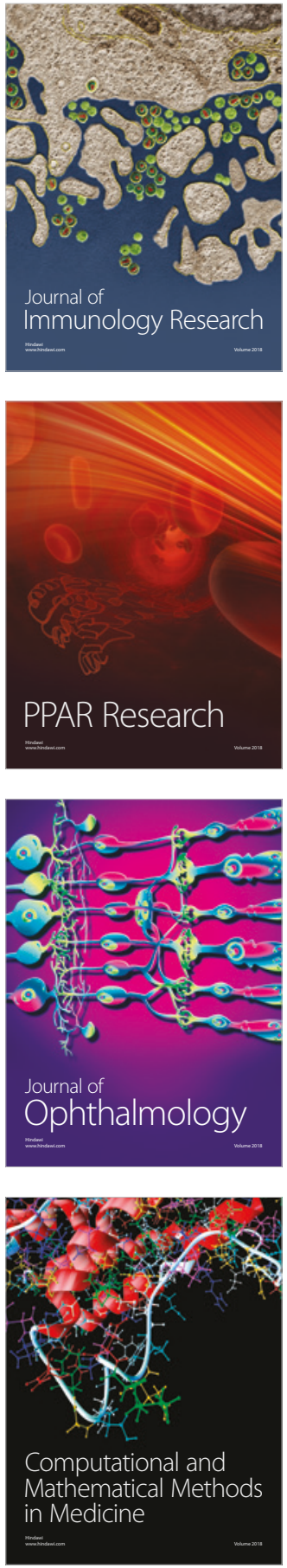

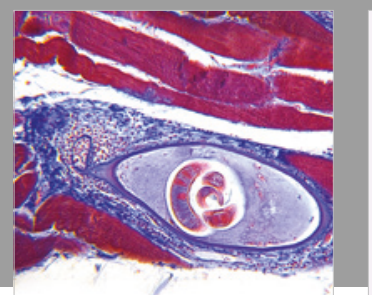

Gastroenterology Research and Practice

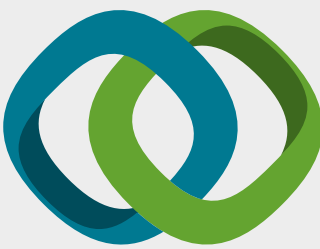

\section{Hindawi}

Submit your manuscripts at

www.hindawi.com
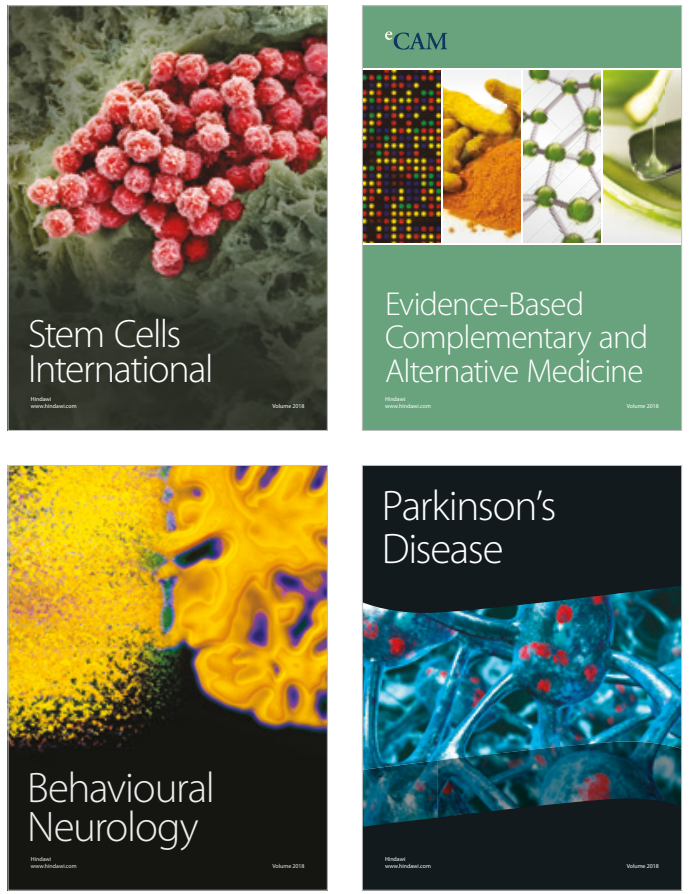

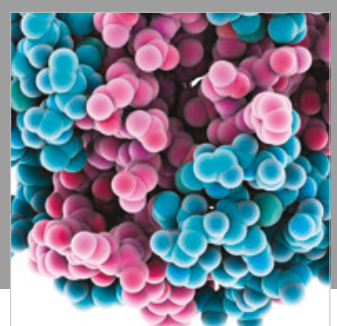

ournal of

Diabetes Research

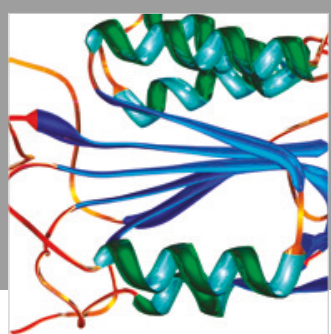

Disease Markers
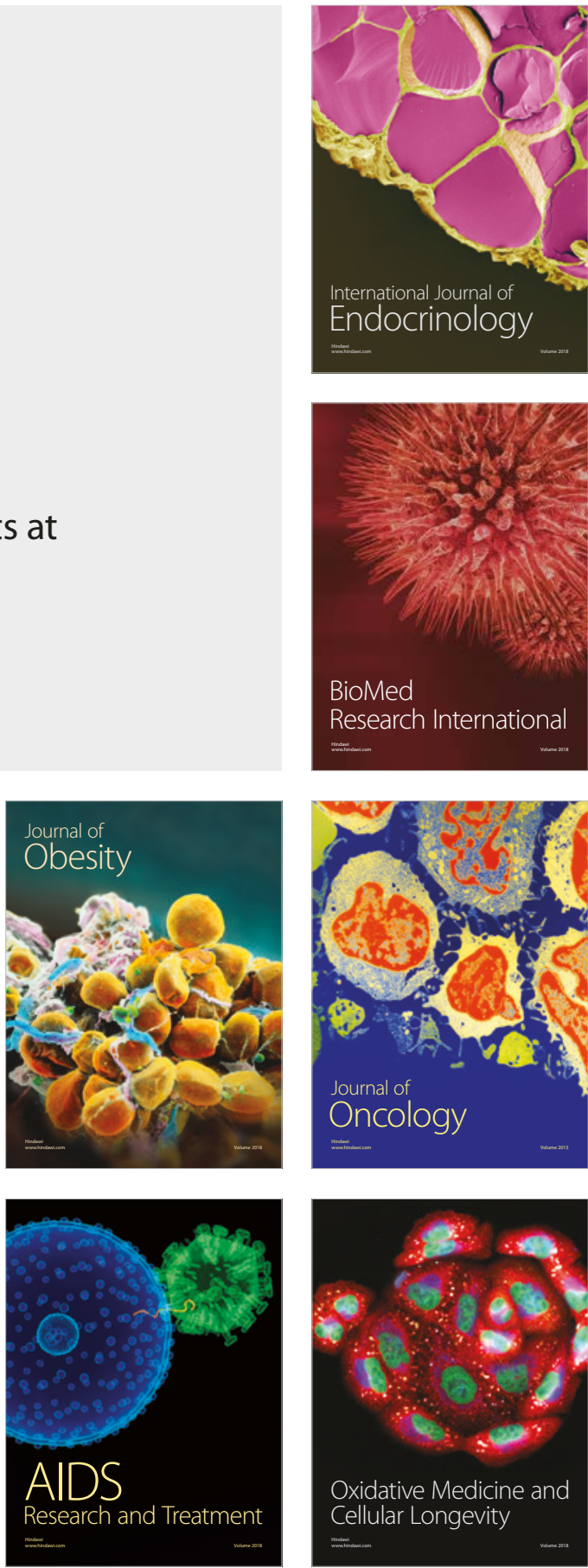